\section{Questión}

Periodismo / Comunicación ISSN 1669-6581
- Av. $44 \mathrm{~N}^{\circ} 676,1^{\circ}$ piso

CP 1900 - La Plata - Argentina

(i) www.perio.unlp.edu.ar/question

\title{
La interdisciplina para el diseño de acciones estratégicas en barrios populares de Argentina ante el COVID-19
}

\section{Interdiscipline for the design of strategic actions in popular neighborhoods of Argentina before COVID-19}

\author{
Tomás Canevari \\ Facultad de Periodismo y Comunicación Social UNLP \\ Instituto de Investigaciones y Ciencias Sociales FaHCE UNLP CONICET \\ tomascanevari@gmail.com
}

\section{Resumen}

Tres incidentes hicieron salirse a la revista académica Question de sus publicaciones tradicionales que realiza desde hace 20 años. Los mismos atraviesan un recorrido personal y nutren un nuevo proyecto de investigación aprobado recientemente por la Agencia Nacional de Promoción Científica y Tecnológica de Argentina. Tejiendo los tres acontecimientos resaltados por la revista, el artículo presenta una lectura del proyecto desde el campo de la comunicación: el tema es el COVID-19 (3), abordado desde una perspectiva de Comunicación / Educación / Cultura con referencia ineludible a Jorge Huergo (2), y tomando como caso de estudio el mismo barrio donde trabajamos ininterrumpidamente junto a un equipo interdisciplinario e inter-actores desde la peor inundación de la historia de la ciudad de La Plata ocurrida en abril de 2013 (1).

\section{Palabras clave}

Educación - Comunicación - Barrios populares - Pandemia 


\section{Summary}

Three incidents led to the Question academic journal of his traditional publications he has been doing for 20 years. They go through a personal journey and nurture a new research project recently approved by the National Agency for Scientific and Technological Promotion of Argentina. Weaving the three events highlighted by the magazine, the article presents a reading of the project from the field of communication: the topic is COVID-19 (3), approached from a perspective of Communication / Education / Culture with inescapable reference to Jorge Huergo (2), and taking as a case study the same neighborhood where we worked uninterrupted together with an interdisciplinary team and inter-actors since the worst flood in the history of the city of La Plata occurred in April 2013 (1).

\section{Keywords}

Education - Communication - Popular Neighborhoods - Pandemic

\section{Introducción}

El nuevo virus que comenzó en la lejana China y se distribuyó en el Planeta con los alcances y las velocidades que los medios de transporte de este mundo hiper globalizado le ofrecía, hizo y hará rediscutir muchos órdenes de la vida. Una de las reacciones inmediatas más destacadas fue la de otorgar a la ciencia un lugar trascendental tanto en la expectativa y esperanza de la población como en la agenda de las gestiones de los gobiernos. En Argentina, Presidencia de la Nación a través de la Agencia Nacional de Promoción Científica y Tecnológica impulsó una convocatoria extraordinaria a la que aplicaron más de 900 equipos de investigación. Entre las 64 iniciativas seleccionadas para su ejecución, forma parte un proyecto elaborado por un equipo de 12 profesionalesi de la UNLP, la UNQ y el CONICET de diversas disciplinas (epidemiología, medicina, geografía, comunicación, informática, arquitectura, historia y astronomía). Se titula "Acciones, protocolos y dispositivos en Barrios Populares de Argentina: Prevención, control y monitoreo del COVID-19. Caso Barrio Puente de Fierro (La Plata, Buenos Aires)".

En su primera etapa, el virus circuló en el mundo a través de pasajeros que volaban por trabajo, turismo $u$ otros motivos entre los cinco continentes y el riesgo se centraba en el contacto con quienes habían viajado recientemente. Con el pasar de las semanas experimentó un fuerte cambio acerca de los principales focos de contagio: de los viajeros del mundo a los sectores más 
vulnerables y desprotegidos de las ciudades. Los mapas actuales concentran la mayor cantidad de casos en barrios y comunidades marginadas. En el caso latinoamericano, deja más en evidencia la desigualdad y los procesos de segregación y fragmentación urbana.

Ante el COVID-19, también aplica la lógica del riesgo como resultado de la combinación de amenaza y vulnerabilidad. El proyecto al que hace referencia este artículo apunta a concentrarse en lo que es la mayor preocupación de decisores políticos y sanitaristas: la circulación del virus en barrios con alta densidad poblacional, necesidades básicas insatisfechas y condiciones precarias del hábitat y las viviendas que, entre otras cosas, dificultan el cumplimiento de la principal medida de prevención en el mundo: el distanciamiento social y el aislamiento.

En Argentina, las respuestas a la pandemia desde el sistema científico encuentran una particular paradoja que desde algunos sectores y medios de comunicación no aparece contextualizada. Hasta hace sólo 6 meses, el gobierno de la alianza Cambiemos se empeñó en desprestigiar el trabajo de científicas/os para finalmente disminuir el rango de ministerio a secretaría, desarticulando y desfinanciando esta área estratégica hasta dejarla en crisis. Así, el Ministerio de Ciencia, Tecnología e Innovación Productiva (Mincyt) que había sido creado el 10 de diciembre de 2007 y había liderado hasta 2015 la expansión del sistema científico tecnológico, que incluyó la repatriación de científicas/os, la construcción de 90 mil metros cuadrados de centros de investigación, el aumento constante de personal administrativo y becas e ingresos a la carrera de investigador científico, pasó a depender del Ministro de Educación y a acoplarse al decrecimiento generalizado del sector público.

De igual manera, la situación del área de Ciencia se repitió con los ministerios de Salud y de Trabajo, degradados a secretarías en 2017 y luego recuperados como ministerios desde el primer día de la gestión del nuevo gobierno en 2019. En medio de la pandemia, no podríamos especificar cuál de estas carteras carga con más responsabilidades y de cuál depende más nuestro presente y futuro.

\section{La convocatoria al sistema científico argentino}

La convocatoria de Presidencia de la Nación a través de la Agencia Nacional de Promoción de la Investigación, el Desarrollo Tecnológico y la Innovación dependiente del Ministerio de Ciencia, Tecnología e Innovación, se orientó a generar aportes para mejorar la capacidad nacional de 
respuesta a la pandemia, priorizando proyectos con resultados aplicables en los primeros 60 días.

Los temas y abordajes son diversos. Por ello, una nube de palabras con los títulos de los 900 proyectos presentados (Figura 1) permite divisar aspectos destacados. Se repiten 347 apariciones del concepto COVID-19; 121 veces desarrollo; 117 SARS-CoV2; 70 pacientes; 68 sistema; 58 detección; 38 plataforma; 37 monitoreo y pandemia; 34 social; 31 control; 30 virus.

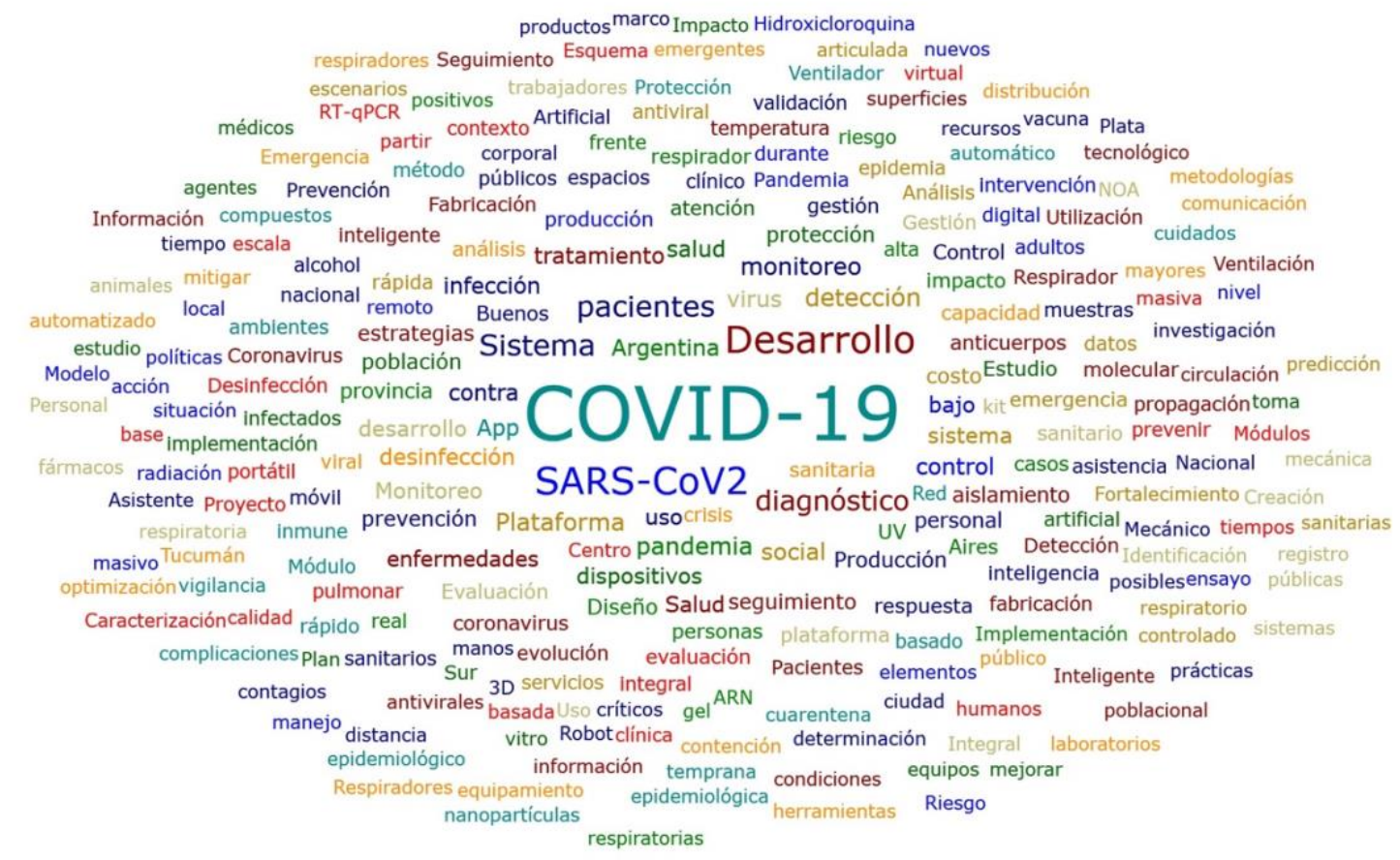

Figura 1. Nube de palabras de títulos de proyectos presentados. El tamaño de la tipografía es en función de la cantidad de apariciones. En la figura aparecen aquellas palabras que se repiten más de 5 veces. Fuente: elaboración propia.

De los 64 proyectos aprobados, una gran mayoría se orienta al trabajo biotecnológico, desarrollo de respiradores, de máscaras faciales y métodos para detectar anticuerpos, entre otros aspectos afines. Ocho proyectos promovidos presentan estudios desde un enfoque social, atendiendo diversas temáticas: distanciamiento, temores y recursos de la población adulta de CABA; información en tiempo real para la detección del COVID-19; trazabilidad de contactos; sistemas de información sanitaria; evaluación de tendencias y escenarios de intervención; prevención y 
monitoreo en el Conurbano Bonaerense; protocolos y dispositivos para barrios populares; y monitoreo del Aislamiento Social Preventivo y Obligatorio.

La siguiente nube de palabras (Figura 2) se trabajó con los títulos de los 64 proyectos seleccionados y se presentan aquellas palabras con más de dos repeticiones. Se destacan 30 apariciones del concepto COVID-19; 27 veces SARS-CoV2; 20 desarrollo; 9 diagnóstico; 7 detección y pacientes; 6 infección y monitoreo; 5 anticuerpos, Argentina, muestras y pandemia; 4 diseño, evaluación, producción, respirador, social y virus.

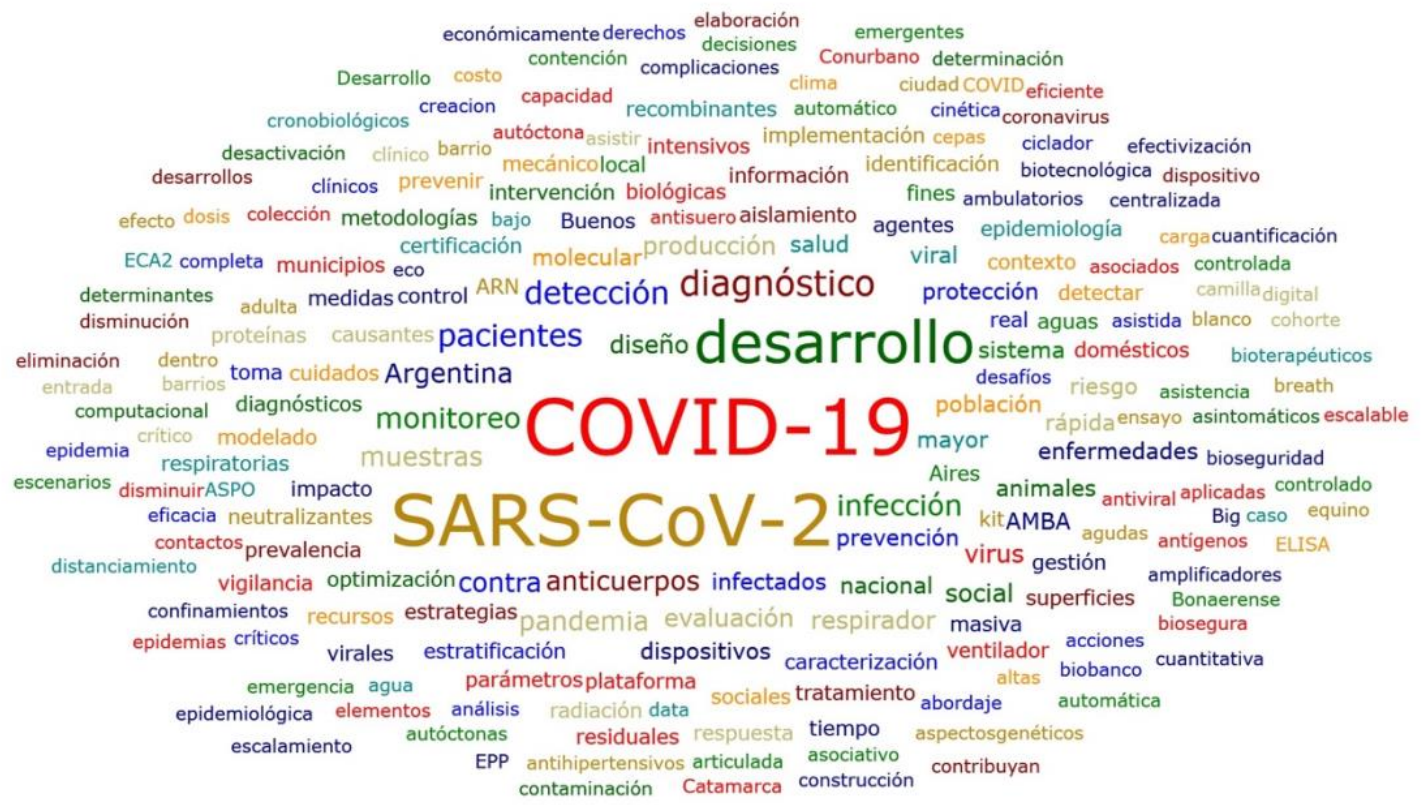

Figura 2. Nube de palabras de títulos de proyectos seleccionados. El tamaño de las palabras resulta de la cantidad de repeticiones en los títulos. La figura presenta aquellas que aparecen al menos dos veces. Fuente: elaboración propia.

Uno de los tantos desafíos para la ciencia ante la emergencia es la superación de la hegemonía disciplinar. Es necesario trabajar articuladamente en nuevas propuestas e iniciativas para nuestras realidades. Demás está aclarar que el desafío es extraordinario y que no existen recetas únicas o soluciones inmediatas. Todas las líneas de acción requieren de la interdisciplinariedad y la ejecución inter-actores. Incluso, para atender esos otros aspectos que la centralidad en el 
nuevo coronavirus deja en segundo o tercer plano y que no pueden perderse puesto que en ciertos casos redundan en la misma preocupación final, el cuidado de la vida: la alimentación, los servicios esenciales para mantener la higiene, el derecho a condiciones de hábitat y vivienda digna, la violencia de género, la atención a enfermedades diversas, entre otras cuestiones.

\section{Comunicación y ciudad}

El virus circuló y circula con velocidad por la gran cantidad de población agrupada en ciudades y vinculada en esta "aldea global" que globaliza de igual manera el virus, pero no los insumos para protegerse, los fondos necesarios para combatirlo, y no sabemos con qué velocidad lo hará con la vacuna si es que ésta se consigue realizar con éxito.

Según la ONU (2018) el 55\% de la población mundial vive en áreas urbanas y se estima que la cantidad de población mundial en ciudades ascienda al 68\% en una proyección hacia 2050 con un crecimiento urbano marcado principalmente en los países de ingresos medios y bajos. Actualmente, las áreas más urbanizadas son América del Norte 82\%, América Latina $81 \%$, Europa $74 \%$, Oceanía $68 \%$ y Asia $50 \%$, la cual concentra a su vez el $54 \%$ de la población urbana mundial. A estos números, cabe agregarle que América Latina es la región más desigual (por ingresos) del mundo con 111 millones de personas habitando viviendas precarias y uno de cada cinco por debajo de la línea de la pobreza (ONU-Hábitat, 2012).

La ciudad y sus dinámicas no pueden reducirse a intervenciones físicas para resolver sus problemas puesto que no se trata sólo un tema de orden espacial y de infraestructuras. Pensar la ciudad desde la comunicación y la cultura no es nuevo, es un claro correlato de la apertura del mediacentrismo que en nuestra región se consolidó en los años ochenta, en esos desplazamientos teóricos que Martín-Barbero consagró en De los medios a las mediaciones, Schmucler en Un proyecto de Comunicación/cultura y Mattelart en Propuesta de una genealogía de la comunicación (Badenes, 2007).

El campo de la comunicación tiene mucho que aportar a la cuestión de las problemáticas urbanas y las lecturas de las tensiones políticas y sociales que hacen a la configuración y planificación urbana y a la producción de conocimiento para la gestión de la pandemia. Es en ciertos territorios donde transcurre la vida en cuarentena y es allí donde se hacen efectivas las prácticas sociales que habrá que readecuar. En el caso de los barrios populares, la inscripción territorial es "un modo de inserción social, un modo de estructuración de las clases populares y una forma de la 
política popular, una vía de conexión con las instituciones y un punto de apoyo para la acción colectiva" (Merklen, 2010, p.21). El conocimiento y re-conocimiento de esos universos simbólicos y prácticas sociales son claves para trazar acciones estratégicas. Las organizaciones barriales y sus lazos de solidaridad que habitualmente permiten la reproducción de la vida social, en este contexto tienen funciones aún más destacadas.

Las interacciones comunicativas (Reguillo, 2000) aparecen en diversos órdenes en la ciudad al estudiar el espacio urbano (la ciudad como lugar antropológico); el espacio público (la ciudad como lugar político); el espacio cotidiano (la ciudad como lugar de producción y reproducción social); y el espacio simbólico (la ciudad como lugar construido como significado) (Cuesta Moreno y Meléndez Labrador, 2017). En suma, la atención está en reconocer territorios, identidades y acciones colectivas para trazar, en red junto a los diversos actores involucrados, posibles medidas y acciones.

Que el virus no discrimina puede ser una verdad aplicable desde un aspecto biológico puesto que reacciona de igual manera, por ejemplo, en laboratorios de cualquier lugar del mundo. En la dimensión social existen otros fenómenos en juego y las posibilidades de prevención y cuidado dependen básicamente de las condiciones de vida.

\section{Acciones protocolos y dispositivos para barrios populares de Argentina}

La principal medida ante la pandemia en Argentina fue iniciar una cuarentena para todo el país con el objetivo de retardar la circulación del virus y contener un contagio acelerado que sature los sistemas de salud. La cualidad de cualquier virus, de necesitar el contacto cercano entre personas para propagarse, hace que el riesgo sea significativamente más amplio en las zonas de mayor densidad poblacional. La Región Metropolitana de Buenos Aires con más de 14 millones y medio de habitantes (INDEC, 2012), concentra el 37\% de la población del país en menos del $1 \%$ del territorio nacional. Esto la convierte en el principal aglomerado urbano del país. En condiciones de vida donde es muy dificultoso el aislamiento por el hacinamiento o porque deben movilizarse en busca de alimentos y otros bienes, la dinámica de transmisión del virus es más alta. Según informa el Gobierno argentino a través de la Secretaría de Integración SocioUrbana (2020), en Argentina se identificaron 4416 barrios populares en donde viven más de 900 mil familias, lo que supera los 4 millones de habitantes. En el caso de la provincia de Buenos Aires, esta situación se repite en 1726 barrios. 
El estudio de caso propuesto en La Plata, a partir del cual se pretende validar un modelo de monitoreo y prevención es Puente de Fierro, el asentamiento informal más grande de los 160 que existen en la ciudad. Allí se parte de un trabajo previo que resulta del recorrido de un equipo interdisciplinario de la UNLP y el CONICET que se inició tras la inundación del 2 de abril de 2013 y que afianzó su trabajo en el barrio a partir de 2016 (Canevari, 2016).

En estos cuatro años de investigación-acción ininterrumpida en Puente de Fierro, se sostuvo una Agenda Científica Participativa (ACP) y una Mesa de Trabajo Permanente (MTP) ejecutada cada mes (43 veces entre 2016 y 2020) denominada "Puente de Fierro Territorio Posible" (Bozzano y Canevari, 2019). Allí se trabaja promoviendo una gobernanza participativa, abierta a quienes deseen sumarse, que atienda los principales problemas detectados y percibidos por los habitantes del lugar (Canevari, Banzato y Cirio, 2019). La elevada vulnerabilidad socioambiental preocupa especialmente ante la amenaza de la pandemia tanto allí como en tantos barrios de similares características sociodemográficas.

El nuevo proyecto pretende consolidar una red comunicacional y vincular a escala barrial para promover la autoprotección (individual, grupal y comunitaria) ante el COVID-19 en articulación con organizaciones, instituciones, comedores, merenderos, cooperativas, iglesias, centros de salud e instituciones educativas. Esta red aspira a permitir optimizar el control y monitoreo del COVID por parte de instituciones públicas, hacer más eficientes los intercambios de insumos, productos y servicios y principalmente, generar un sistema de vigilancia epidemiológica comunitaria para monitorear y contener posibles focos de contagio, contemplando que el virus seguirá circulando a lo largo del tiempo.

Se propone, a su vez, afianzar la llegada al barrio de las políticas y asistencias extraordinarias del Estado co-construyendo los mejores modos de acceso respetando el cumplimiento del aislamiento. El desafío está en mejorar redes de autocuidado y circulación de información, y en generar opciones y alternativas útiles a tomadores de decisión. La posibilidad radica en desarrollar iniciativas junto a habitantes del barrio, que incluyan e interpelen sus realidades.

\section{Componente de la Comunicación/Educación/Cultura}

"Comunicación/Educación significan un territorio común, tejido por un estar en ese lugar con otros, configurados por memorias, por luchas, por proyectos. Significan el reconocimiento del otro en la trama del 'nos-otros'. Significa un encuentro y reconstrucción permanente de sentidos, 
de núcleos arquetípicos, de utopías, transidos por un magma que llamamos cultura" (Huergo, 1997). Este abordaje comprende los campos de la comunicación y la educación en un sentido amplio, que atienda los desafíos actuales de nuevas significaciones y formas de vincularse.

El proyecto tiene un fuerte componente de la comunicación/educación/cultura puesto que se trata de abordar procesos y prácticas que se dan en la interrelación entre cultura y política donde se ponen en juego las prácticas sociales de Comunicación (a través de las cuales los sujetos se vinculan) y de Educación (a través de las cuales los sujetos se expresan o se liberan) (Huergo, 1997).

La situación excepcional no trastoca la cualidad de la comunicación como producción social de sentidos, y el hecho de que dichos sentidos se encuentren sostenidos y enredados en la cultura. De allí que sea necesario construir un saber situado que en palabras de Freire (1970) se proponga partir del "aquí y ahora" del otro.

En otras palabras, se apunta a generar nuevos conocimientos, no sólo a partir de conocer sino de re-conocer las prácticas socioculturales que permitan propiciar una identificación con las acciones estratégicas a adoptar. No hay modo de que las medidas frente a la pandemia no involucren a la sociedad como protagonista. En este sentido el proceso es educativo porque propone una reafirmación o una transformación de las prácticas. Reconocimiento e intervención irán en forma simultánea: no existe interpelación o transformación individual ni colectiva si no hay un reconocimiento de los sujetos en aquello que se propone.

\section{Reflexiones preliminares}

Se destaca la importancia de recuperar el Estado, revirtiendo la difamación y degradación efectuada durante la anterior gestión de gobierno sobre las áreas en las que depositamos especial exigencia y expectativa actualmente. A su vez, los saberes son requeridos tanto en los debates científicos como en las decisiones estatales, por lo que la realidad exige a las ciencias repensar la clasificación tan compartimentada y trabajar en la integración transdisciplinar. Asimismo, convoca a superar la instancia de la crítica para promover fases propositivas de praxis que combinen acción y reflexión sobre la marcha.

La mundialización del virus no reduce la importancia del saber situado. Las organizaciones son el principal sostén de redes de sociabilidad en los barrios populares y su rol es fundamental. Por otra parte, el reconocimiento de prácticas sociales dará mayores herramientas para delinear 
acciones estratégicas que se ajusten al territorio abordado y permitan diseñar producciones comunicacionales adecuadas.

Queda clara la necesidad del enlace entre lo individual, lo social y lo estatal para la gestión de la pandemia. Para ello, es difícil pero urgente contrarrestar la paranoia y la psicosis social en estos tiempos de incertidumbre y aislamiento, así como las prácticas de discriminación y estigmatización que avanzan como ocurrió con otras enfermedades en el pasado reciente $(\mathrm{VIH}$, tuberculosis, lepra, otras) y que necesitaron del correr del tiempo y la concientización para recibir un repudio social. Esas formas no sólo degradan nuestras sociedades, sino que además atentan contra las medidas posibles de monitoreo y prevención. La salida es colectiva, requiere de fuertes lazos de solidaridad y de construcción de comunidad aún en el aislamiento.

\section{Bibliografía}

Badenes, D. (2007). Comunicación y ciudad: Líneas de investigación y encuentros con la historia cultural urbana. Question, 1(14). https://perio.unlp.edu.ar/ojs/index.php/question/article/view/354 Bozzano, H., y Canevari, T. (2019). Scientific Agendas and Work Tables. An action research initiative in La Plata, Ensenada and Berisso, Argentina. International Journal of Action Research, 25-46.

Canevari, T. (2016). Disputas de sentidos y reconfiguración de lo social: La co-construcción de una Agenda Científica de Intervención y Transformación a partir de la trágica inundación del 2 de abril de 2013 en el Gran La Plata. Actas de Periodismo y Comunicación, 2, n.o 1. http://hdl.handle.net/10915/60517

Canevari, T., Banzato, G., y Cirio, G. (2019). Percepciones de vecinos sobre problemas sociales y ambientales en el Gran La Plata, Argentina. Hacia una agenda de Gestión Integral del Territorio. Territorios, O(40), 53-82. https://doi.org/10.12804/revistas.urosario.edu.co/territorios/a.6372 Cuesta Moreno, O. J., y Meléndez Labrador, S. (2017). Comunicación urbana: Antecedentes y configuraciones de líneas de investigación en América Latina y España. Territorios, 37, 205-228. Freire, P. (1970). Pedagogía del oprimido. Siglo XXI.

Huergo, J. (1997). Comunicación y educación: Aproximaciones. En Comunicación/Educación. Ámbitos, prácticas y perspectivas. Ediciones de Periodismo y Comunicación.

INDEC. (2012). Censo Nacional de Población, Hogares y Viviendas 2010: Censo del Bicentenario: Resultados definitivos, Serie $B \quad n_{0}$ 2. INDEC. 
https://www.indec.gov.ar/censos_provinciales.asp?id_tema_1=2\&id_tema_2=41\&id_tema_3=13 $5 \& p=06 \& d=999 \& t=3 \& s=0 \& c=2010$

Kaplún, M. (2002). Una pedagogía de la comunicación (el comunicador popular). Caminos.

Merklen, D. (2010). Pobres ciudadanos. Las clases populares en la era democrática (Argentina, 1983-2003) (2da ed.). Gorla.

ONU-Habitat. (2012). Estado de las ciudades de América Latina y el Caribe 2012. Rumbo a una nueva transición urbana (Programa de las Naciones Unidas para los Asentiamientos Humanos). ONU-Habitat.

ONU DAES (2018). Las ciudades seguirán creciendo, sobre todo en los países en desarrollo. ONU DAES | Naciones Unidas Departamento de Asuntos Económicos y Sociales. https://www.un.org/development/desa/es/news/population/2018-world-urbanizationprospects.html

Reguillo Cruz, R. (2000). Ciudad y comunicación. La investigación posible. En Lo viejo y lo nuevo. Investigar la comunicación en el Siglo XXI (pp. 33-49). Ediciones De la Torre.

Secretaría de Integración Socio-Urbana (2020). Barrios Populares [Sitio oficial de gobierno, Ministerio de Desarrollo Territorial y Hábitat]. Argentina.gob.ar. https://www.argentina.gob.ar/noticias/barrios-populares

\section{Nota}

\footnotetext{
i Por orden alfabético: Babbini Ignacio, Bourgeois Marcelo, Bozzano Horacio (director), Campuzano Castro Federico, Canevari Tomás, Etchegoyen Graciela, Fonseca Jenny, Aramburu Itziar, Marín Gustavo, Mateo Graciela, Rodríguez Tarducci Rocío y Vetere Pablo. El proyecto lo integran también 13 organizaciones barriales y esta conformación inicial se ampliará durante la ejecución.
} 